\title{
Percepções dos professores do desporto escolar sobre a relação entre o sector escolar e o sector federado da Região Autónoma da Madeira
}

\author{
Jorge Soares
}

\author{
Departamento de Educação Física e Desporto \\ Universidade da Madeira \\ Portugal
}

\section{RESUMO}

A Lei Quadro do Sistema Desportivo da Região Autónoma da Madeira( ${ }^{(5)}$ defende que o desporto escolar deve ser desenvolvido numa relação de articulação com o desporto federado. O estudo seguiu dois objectivos: detectar se os professores envolvidos em cargos no desporto escolar na Madeira também estavam envolvidos no sector federado e conhecer as percepções dos mesmos sobre a relação que deve existir entre ambos os sectores. A amostra contabilizou um total de 255 participantes, representando $98 \%$ do universo dos professores do desporto escolar. Para a recolha dos dados foi utilizado um questionário, construídos a partir do estudo de Correia \& Rosado ${ }^{(4)}$ e adaptado à Madeira a partir do seu programa de actividades ${ }^{(7)}$. O tratamento dos dados fez-se através do SPSS e da técnica não paramétrica de independência do Qui-quadrado $(p=0,05)$.

Os resultados identificaram um total de 117 professores $(45,9 \%)$ envolvidos em cargos no sector federado, sendo o cargo de treinador e a modalidade de futebol, aqueles que maiores percentagens colheram, $73,5 \%$ e $30,7 \%$, respectivamente. A maioria dos inquiridos $(51,8 \%)$ acha que deve existir uma relação mais próxima, de articulação e de cooperação entre o sector escolar e o federado, contra $24,7 \%$ que acham que não, e $21,2 \%$ que optaram por não expressar a sua convicção. Os resultados evidenciaram diferenças significativas entre o grupo dos professores que estavam ligados ao desporto federado e o grupo dos professores que não tinha ligação ao federado $(\mathrm{p}=0,003)$. De realçar ainda que dos 124 professores que não estavam envolvidos no sector federado, 54 (43,5\%) são a favor de uma relação de proximidade entre ambos os sectores. Em conclusão, os resultados sugerem uma maior articulação e cooperação entre os sectores escolar e federado.

Palavras-chave: desporto escolar, desporto federado, cooperação, organização, professores

\author{
ABSTRACT \\ Teacher's perceptions of school sport regarding the relation \\ between school and federated sector in the Autonomous Region \\ of Madeira
}

The Sports System Law Framework of Autonomous Region of Madeira(5) argues that school sports should be developed in articulation with the federated sport. The study carried out and presented hereunder had two main objectives: to determine if the teachers involved in school sports positions in Madeira were also involved in the federated sector and also to identify their perceptions concerning the relationship that should exist between both sectors.

The sample covered a total of 255 participants, representing $98 \%$ of the universe of teachers in school sports. The questionnaire used to collect the data was put together departing from the study of Correia $\&$ Rosado ${ }^{(4)}$ and adapted to Madeira in accordance with its programme of activities ${ }^{(7)}$. Data was processed with SPSS and the independence non-parametric technique of the chi-square $(p=0.05)$. The results show a total of 117 teachers (45.9\%) involved in the federated sector, and the positions of coach and football modality were the ones that scored the highest percentages, $73.5 \%$ and $30.7 \%$ respectively. The majority of the respondents (51.8\%) think there should be a closer relationship, in the form of articulation and cooperation between the federated and school sector, against $24.7 \%$ who do not agree with this point of view, and $21.2 \%$ who chose not to express their position. The results also show significant differences between the group of teachers who were linked to federated sport and the group of teachers who had no connection with it $(p=0.003)$. Furthermore, from the 124 teachers who were not involved in the federal sector, 54 (43.5\%) are in favour of a closer relationship between both sectors. In conclusion, the results suggest greater coordination and cooperation between the federated and school sectors.

Key-words: school sport, federated sport, cooperation, organization, teachers 


\section{INTRODUÇÃO}

A Lei de Bases da Actividade Física e do Desporto(9), bem como assim, a Lei de Bases do Sistema

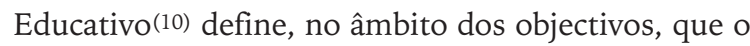
desporto escolar deve ser entendido como um factor de cultura. E, só poderá sê-lo, se considerarmos o desporto como um fenómeno social e total, onde a vertente educativa e formativa está em primeiro lugar. Assim, e de acordo com uma análise sistémica e de desenvolvimento do fenómeno desportivo, as actividades que se desenvolvem no âmbito educativo não devem estar dissociadas das actividades que se realizam no âmbito do contexto sociocultural e desportivo, seja na vertente federada-competitiva, seja na vertente de lazer e recreação. O desporto escolar deve, assim, ser entendido como um sector autónomo do sistema educativo, mas também deve manter estreitas e dinâmicas interacções com as actividades que se realizam nos restantes sectores, entre os quais o sector federado $(1,3)$.

No caso específico da Região Autónoma da Madeira, e seguindo as oportunidades consagradas no seu Estatuto Político-Administrativo(11), o Governo Regional levou à Assembleia Legislativa, a proposta de Lei Quadro do Sistema Desportivo da Madeira(5), que viria a ser aprovada por maioria. Neste diploma constata-se que existe uma intenção do Governo Regional no sentido do desporto escolar vir a assumir uma estreita ligação ao desporto que se desenvolve nos clubes federados. Por exemplo, no artigo $19^{\circ}$ - actividades conjuntas, defende que os clubes e associações federadas articulam as suas intervenções de modo a favorecer o contacto entre as áreas do desporto escolar e as do desporto federado, através da implementação de actividades conjuntas, dotadas de regulamentação técnico-pedagógica apropriada, sem prejuízo da concretização das actividades específicas de cada um dos sectores. De certa forma, esta visão integrada, reconhece à escola, um papel relevante na formação desportiva dos mais jovens e na sua articulação com o desporto que se faz na sociedade. Nesta abordagem integrada do desporto desta$\operatorname{camos}^{(6)}$, quando defende uma forte ligação da escola ao desporto na sociedade e o desporto escolar como um viveiro de formação de praticantes para o desporto federado.
O desporto escolar e as orientações que estão subjacentes à sua organização, dinâmica e qualidade do serviço, envolvem necessariamente uma dimensão política(6). Defende, por um lado, que as questões da qualidade do serviço público precisam de ser analisadas e compreendidas na perspectiva da decisão política para o serviço público, e por outro na diferença entre o serviço prestado e a qualidade do serviço percepcionado pelos clientes e intervenientes. Igualmente, mas no âmbito da avaliação dos serviços profissionais do sector privado(12), defende uma relação continuada e consistente na avaliação das expectativas e dos resultados da satisfação dos clientes. Neste contexto, as expectativas e percepções dos principais actores envolvidos na organização desportiva são determinantes para se percepcionar a qualidade do serviço e melhorar os seus atributos $(8,14)$. Dentro da organização do desporto escolar, os professores que desempenham cargos específicos: coordenador ou gestor desportivo, orientador de equipa e coordenador de actividade interna, constituem os actores mais privilegiados para avaliarem a qualidade do serviço.

Segundo Chelladurai(2), a qualidade do serviço das actividades físicas e desportivas passa por determinar o grau de satisfação e de percepção dos intervenientes. Ademais, sabendo-se que há uma década atrás, mais de metade dos professores envolvidos no desporto escolar também estavam envolvidos no desporto federado na qualidade de treinadores(15), importa conhecer até que ponto esta acumulação continua. Assim, o estudo seguiu dois objectivos: detectar se os professores envolvidos em cargos no desporto escolar na Madeira também estavam envolvidos no sector federado e conhecer as percepções dos mesmos sobre a relação que deve existir entre ambos os sectores.

\section{MATERIAL E MÉTODOS}

Foi constituída uma equipa de sete investigadores, aproveitando-se as mais-valias proporcionadas pelos recursos humanos do Gabinete Coordenador do Desporto Escolar e pelos alunos do Curso de Mestrado em Educação Física e Desporto (edições 2005/2006 e 2006/2007).

Esta dupla colaboração permitiu alcançar um total de 255 professores de Educação Física que exerciam fun- 
ções específicas no desporto escolar, correspondente a $98 \%$ do universo dos professores (260). Se tivermos em conta o total dos professores de Educação Física a leccionar em todas as escolas públicas e privadas dos $2^{\circ}$ e $3^{\circ}$ ciclos e ensino secundário na Região Autónoma da Madeira (476), a amostra corresponde a 53,6\%. Foi elaborado um questionário de avaliação da qualidade do serviço com base no instrumento desenvolvido no estudo realizado em Portugal Continental(4), posteriormente adaptado e validado à orgânica e regulamentação do desporto escolar da Madeira(7).

Para apurar a fiabilidade do questionário utilizou-se a técnica de Alpha de Cronbach tendo-se verificado a existência de fiabilidade interna adequada para cada uma das variáveis em análise.

A aplicação do questionário foi feita através de uma reunião de carácter obrigatório tendo sido orientada pelos respectivos elementos da equipa de investigação que prestaram os esclarecimentos e asseguraram a recolha e imediata do instrumento. No que diz respeito aos procedimentos estatísticos recorremos ao software SPSS (Statistical Package for the Social Sciences) versão 15.0 for Windows e ao programa Microsoft Office Excel versão 11.0. Dada a natureza da maioria das variáveis - do tipo nominal e ordinal, recorremos à utilização de técnicas não paramétricas, nomeadamente, o teste do Qui-Quadrado, e o teste Mann-Whitney, para uma probabilidade de erro de 0,05.

\section{RESULTADOS}

\section{Envolvimento dos professores do desporto escolar no sector federado}

A participação e acumulação de funções dos professores do desporto escolar no sector federado pode ser um factor relevante para o conhecimento e desenvolvimento da relação entre os dois sectores. Nessa medida procuramos conhecer até que ponto os professores do desporto escolar estavam ligados também ao sector federado, e verificámos que, 117 $(45,9 \%)$ dos professores, durante o ano lectivo 20062007, estiveram ligados a um clube fora da escola, contra 129 (50,6\%).

Constatou-se que o cargo desempenhado no sector federado que maior resultado colheu foi o de treinador/monitor com um valor de $73,5 \%$, seguido do de atleta com 10,26\% e do de Dirigente/Coordenador com $9,4 \%$ (Figura 1).
A análise da participação dos professores no sector federado, de acordo com as modalidades desportivas, permitiu-nos destacar a de futebol como aquela que colheu maior preferência dos professores $(30,7 \%)$, seguido do voleibol $(11,4 \%)$ e da natação $(8,7 \%)$, resultados muito similares aos das modalidades desportivas no sector escolar.

\section{Articulação do desporto escolar com o desporto federado} Confrontados com a questão "Considera que o desporto escolar na sua escola deveria ter uma relação mais próxima (articulada/interligada cooperante) com o DF?", 132 (51,8\%) dos professores responderam afirmativamente, contra $63(24,7 \%)$ que disseram que não. Os resultados indicam-nos ainda mais um resultado interessante e preocupante: 54 $(21,2 \%)$ preferiam não emitir qualquer resposta. No sentido de se procurar uma justificação plausível para a percentagem de $51,8 \%$ a concordar com uma maior proximidade entre ambos os sectores, avançou-se com o Chi-Square Test a fim de verificar se os professores que estavam envolvidos no sector federado eram os que mais defendiam a relação de proximidade. Os resultados do Quadro 1 confirmam que existem diferenças significativas $(p=0,003)$ entre os dois grupos de professores, sendo os que estão ligados ao sector federado aqueles que defendem uma articulação mais próxima.

Todavia, o Quadro 1 também nos mostra que, do grupo dos professores que não estão envolvidos no sector federado, 54 deles $(43,5 \%)$ consideram que deveriam haver uma relação mais próxima.

\section{Dinamismo na conquista de parceiros externos}

Uma maior articulação e interacção entre os dois sectores desportivos pode ser explicada a partir da identificação da dinâmica das escolas na conquista de parceiros externos. Os resultados obtidos sobre esta questão revelaram que quase metades dos docentes $(45,5 \%)$ não evidenciaram opinião, o que pode significar desconhecimento da existência de parceiros externos ou displicência em relação à questão. Por outro lado, daqueles que se pronunciaram, $29,4 \%$ dizem haver dinamismo e $22,4 \%$ considera a sua escola pouco activa na conquista de parceiros externos (Quadro 2). 


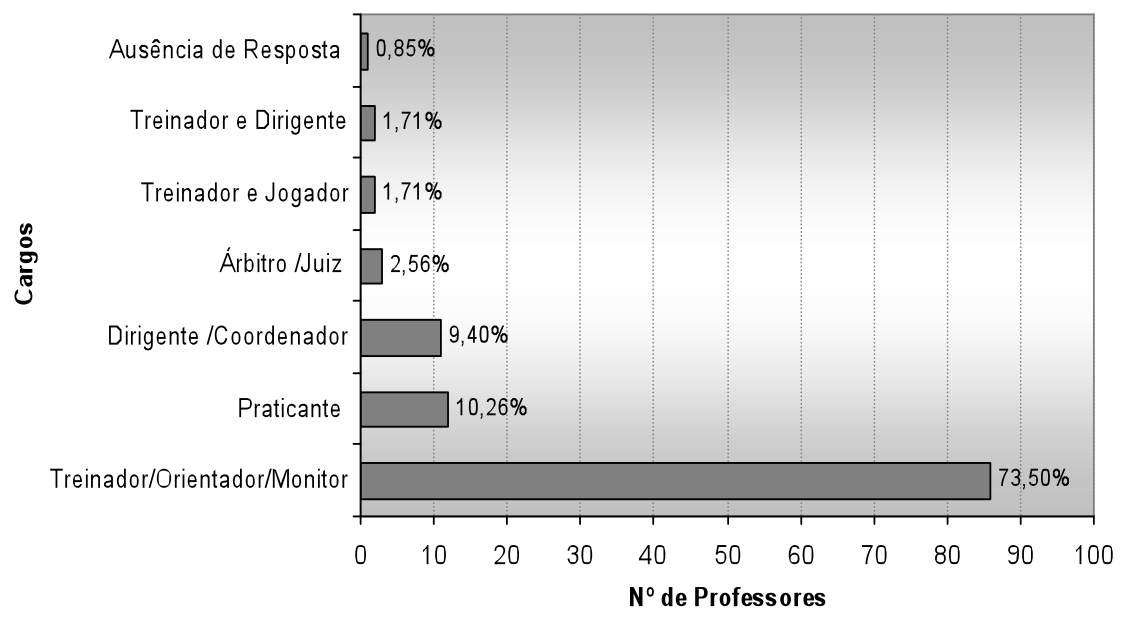

Figura 1. Cargos ocupados no sector federado pelos professores do desporto escolar

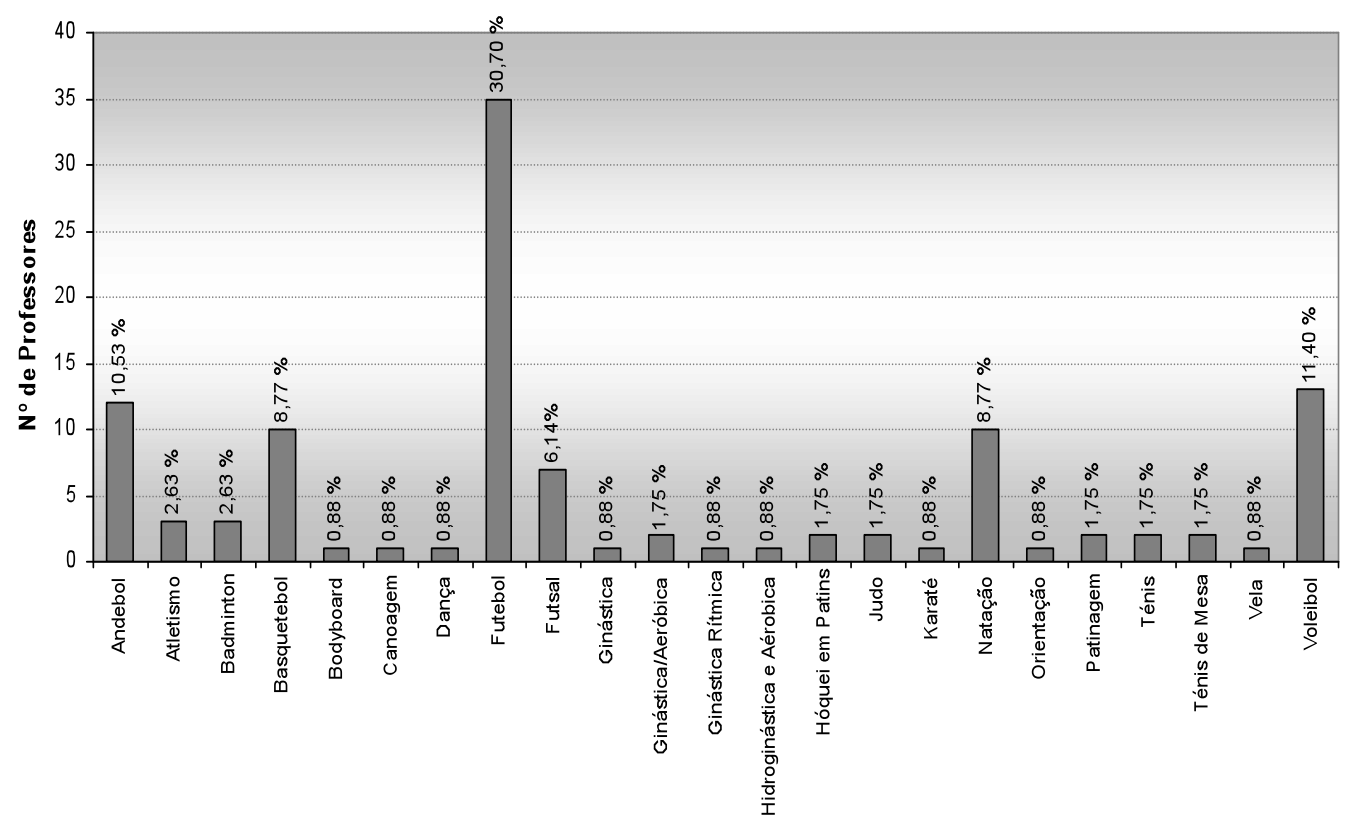

Figura 2.

Modalidades desportivas do sector federado onde estão envolvidos os professores

Dos 75 que acharam que a escola é dinâmica na conquista de parceiros externos a maior percentagem $(33,3 \%)$ apontou os clubes e associações desportivas como organizações parceiras.

\section{DISCUSSÃO}

Os resultados apurados sugerem claramente uma maior articulação e cooperação entre o sector desportivo escolar e o sector federado e estão em con- cordância com as novas orientações definidas na Lei Quadro do Sistema Desportivo da Região Autónoma da Madeira(5) quando advoga uma maior dinâmica de interacção e articulação do trabalho da escola com as actividades dos clubes e associações desportivas. Os resultados também confirmam um envolvimento elevado, com mais de $50 \%$ dos professores do desporto escolar a exercer funções específicas no desporto federado. Os mesmos resultados já tinham 
Quadro 1. Relação entre a percepção que os professores têm da articulação desporto escolar-desporto federado e o envolvimento/não envolvimento dos mesmos nos clubes federados

\begin{tabular}{|c|c|c|c|c|c|}
\hline \multirow{2}{*}{ Questão } & & \multirow{2}{*}{ Indicadores } & \multicolumn{2}{|c|}{ Envolvido num clube? } & \multirow{2}{*}{$\begin{array}{l}\text { Total } \\
\text { Não }\end{array}$} \\
\hline & & & Não & Sim & \\
\hline \multirow{9}{*}{$\begin{array}{l}\text { Desporto escolar deve ter } \\
\text { uma relação mais próxima } \\
\text { com o desporto federado? }\end{array}$} & \multirow{3}{*}{ Sem opinião } & $\mathrm{n}$ & 33 & 18 & 51 \\
\hline & & $\%$ & $26,6 \%$ & $15,5 \%$ & $21,3 \%$ \\
\hline & & Valor residual & 1,3 & $-1,3$ & \\
\hline & \multirow{3}{*}{ Sim } & $\mathrm{n}$ & 54 & 76 & 130 \\
\hline & & $\%$ & $43,5 \%$ & $65,5 \%$ & $54,2 \%$ \\
\hline & & Valor residual & $-1,6$ & 1,7 & \\
\hline & \multirow{3}{*}{ Não } & $\mathrm{n}$ & 37 & 22 & 59 \\
\hline & & $\%$ & $29,8 \%$ & $19,0 \%$ & $24,6 \%$ \\
\hline & & Valor residual & 1,2 & $-1,2$ & \\
\hline \multirow{2}{*}{ Total } & & $\mathrm{n}$ & 124 & 116 & 240 \\
\hline & & $\%$ & $100,0 \%$ & $100,0 \%$ & $100,0 \%$ \\
\hline$\chi^{2}=11,695$ & & g.l. $=2$ & \multicolumn{2}{|c|}{ Sig. $=0,003$} & \\
\hline
\end{tabular}

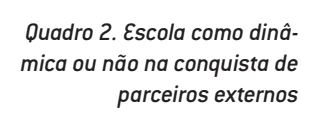

\begin{tabular}{lll}
\hline Respostas & N & $\%$ \\
\hline Sem opinião & 116 & 45,5 \\
Sim & 75 & 29,4 \\
Não & 57 & 22,4 \\
Ausência de Resposta & 7 & 2,7 \\
\hline Total & 255 & 100,0 \\
\hline
\end{tabular}

sido apurados no ano lectivo de 1994/1995 quando ${ }^{(15)}$ constatou que $54 \%$ dos docentes do desporto escolar também estavam ligados ao sector federado, especialmente na função de treinador.

No entanto, é o grupo dos professores que está envolvido em funções mo desporto federado, quem mais defende uma relação de aproximação entre ambos os sectores, comparativamente com o grupo de docentes que não estava envolvido no sector federado. O conhecimento que os professores detêm pelo facto de estarem envolvidos em ambos os sectores, e as potencialidades de interacção, podem ser duas possíveis explicações para esta convicção dos docentes. Tal como sugerem autores que têm reflectido e escrito a interacção entre o sector escolar e o sector federado $(1,3,13,16)$, as dinâmicas e as sinergias que se criam entre ambos os sectores, devem superar claramente os conflitos e adversidades, e acrescentar mais valias para a qualidade da formação e competição desportivas dos mais jovens.

$O$ estudo também evidencia um resultado muito interessante: do grupo dos professores que não estava envolvido no sector federado, constatou-se que uma percentagem elevada $(43,5 \%)$ foi no sentido de concordar com a relação de aproximação e de interacção entre ambos os sectores.

Uma das interpretações plausíveis para estes resultados é o de que a escola pode e deve ter um papel relevante na formação desportiva inicial e na sua relação de intercomplementaridade com o papel dos clubes federados ${ }^{(3,6)}$. Supostamente, os professores que estão envolvidos nos clubes esperam e anseiam 
que haja uma maior dinâmica de cooperação e articulação entre ambos os sectores. Conforme modelo organizacional proposto por Pires(13), o desporto na escola constituiu uma zona de interface e de projecção do atleta para a vida e para a competição, e neste sentido o trabalho do desporto escolar não pode ficar indiferente ao que se faz no desporto federado.

Dos 117 professores que também estão ligados ao desporto federado, $73,5 \%$ desempenham o papel de treinador ou monitor desportivo. É de realçar que há cerca de dez anos atrás Soares(15), também já tinha constatado que uma percentagem elevada (69\%) dos professores envolvidos no sistema desportivo, desempenhava o cargo de treinador desportivo. Havendo esta duplicidade de funções é pertinente questionar o aproveitamento ou não desta oportunidade, seja numa perspectiva de continuidade da prática desportiva dos jovens quando transitam do escolar para o federado, seja ao nível da optimização dos recursos humanos e das sinergias que resultam da participação conjunta dos praticantes nas respectivas competições. Contudo, é necessário considerar os princípios de interacção e clarificar o papel de ambos os sectores, para que haja uma relação de cooperação, de complementaridade, e não de crispação ou de conflito. Os resultados também colocam em evidência a necessidade das escolas conquistarem parcerias externas e optimizarem os recursos com os clubes e associações desportivas federadas. O incremento dos clubes desportivos escolares poderá ser uma estratégia de desenvolvimento da organização interna das escolas no sentido de uma melhoria substancial da qualidade do serviço(16). Para tal, é necessário que se criem sinergias e autonomia suficiente para que os actores organizacionais possam desenvolver as suas competências e interagir com as actividades desenvolvidas pelas associações e clubes, num contexto mais amplo da organização das actividades desportivas para jovens.

\section{CONCLUSÃO}

Os resultados do estudo leva-nos a concluir que os professores envolvidos em funções específicas no desporto escolar defendem uma relação mais próxima e uma interacção de cooperação entre o sector do desporto escolar e o sector do desporto federado. Esta relação não só é defendida por aqueles profes- sores que estão também envolvidos em funções específicas no desporto federado, como também pelos que apenas exercem funções no sector escolar. Os resultados do estudo indiciam uma fraca e preocupante relação da escola na conquista de parceiros externos para o desporto escolar.

\section{AGRADECIMENTOS}

O autor do estudo agradece a colaboração: do Gabinete Coordenador do Desporto Escolar da Direcção Regional de Educação da Madeira; dos professores do desporto escolar das escolas do $2^{\circ}$ e $3^{\circ}$ ciclos e do ensino secundário da Região Autónoma da Madeira; das professoras Júlia Andrade e Sandra Godinho e dos estudantes do Mestrado em Educação Física e Desporto da Universidade da Madeira: Jorge Camacho, Duarte Sumares, Hélio Antunes, Ana Sampaio, Isabel Vieira, Miguel Saldanha e Ricardo Santos.

\section{CORRESPONDÊNCIA}

\section{Jorge Soares}

Departamento de Educação Física e Desporto - Piso 1 Campus Universitário da Penteada, Universidade da Madeira

9000-390 Funchal

Telef.: 962566517; 291705321.

E-mail: j.soares@uma.pt 


\section{REFERÊNCIAS}

1. Bento J (1985). Desporto na escola e desporto no clube possibilidades de uma cooperação. Horizonte. V. II(1): 3-6.

2. Chelladurai P (2006). Human Resource Management in Sport and Recreation. Human Kinetics, 2nd edition.

3. Coelho O (1989). Desporto escolar e desporto federado, algumas reflexões necessárias. Horizonte VI, (4/5): 152153.

4. Correia A, Rosado A (2006). A Satisfação da Comunidade Escolar e das Famílias relativamente ao desporto escolar. Estudo realizado no âmbito do protocolo entre a Direcção Geral de Inovação e Desenvolvimento Curricular e a Faculdade de Motricidade Humana, Lisboa - Portugal.

5. Decreto Legislativo Regional n. ${ }^{\circ}$ 4/2007/M, de 11 de Janeiro. Lei Quadro do Sistema Desportivo da Região Autónoma da Madeira. Diário da República Série I - N. ${ }^{\circ}$, 277-286.

6. Garcia R (2005). Escola, Educação Física e Tempo Livre: um relação também da Gestão Desportiva. Gestão do Desporto, Associação Portuguesa de Gestão do Desporto, Ano 2 (2 Julho): 12-28.

7. GCDE (2006). Programa do Desporto Escolar 2006/2007Madeira. Direcção Regional de Educação, Gabinete Coordenador do Desporto Escolar. www.madeiraedu.pt/dre/gcde, Dezembro de 2006.
8. Gronroos, C. (1984). A Service quality model and its marketing implications. European Journal of Marketing 18(4): 36-44.

9. Lei n. ${ }^{\circ} 5 / 2007$, de 16 de Janeiro. Lei de Bases da Actividade Física e do Desporto. Diário da República I SérieN. ${ }^{\circ} 11,356-363$.

10. Lei n. ${ }^{\circ} 49 / 2005$, de 30 de Agosto. Lei de Bases do Sistema Educativo, Diário da República I Série A, N. ${ }^{\circ} 166$.

11. Lei n. ${ }^{\circ}$ 130/99, de 21 de Agosto, Estatuto PolíticoAdministrativo da Região Autónoma da Madeira, Diário da República n. ${ }^{\circ} 169$, de 22 de Julho de 1999.

12. Ojasalo J (2001). Managing customer expectations in professional services, Managing Service Quality 11(3): 200 - 21.

13. Pires G (1994). Desporto escolar - desenvolvimento e gestão de projectos. U.T.L., Faculdade de Motricidade Humana, Departamento de Ciências do Desporto, Lisboa.

14. Robinson L (2006). Customer expectations of sport organisations. European Sport Management Quarterly 6(1): 67-84.

15. Soares J (1997). Desporto Escolar - organização e perspectivas futuras. Edição o Desporto Madeira. Funchal.

16. Soares J (2001). Sport in the School Environment: the role of the sport club. (Second prize of the Best Poster Award). Congresso da Association International Des Écoles Supérieurs D'Education Physique e Universidade da Madeira Funchal.

17. Walsh K (1991). Quality and public services. Public Administration 69(4): 503-514. 